\title{
Percepções sobre o papel das políticas públicas relacionadas ao trabalho e responsabilidades familiares
}

\author{
Perceptions about the role of public policies related
} to work and family responsibilities

\author{
Andrea de Sousa Gama* \\ Lia de Mattos Rocha** \\ Karolyne Romero de Alcantara***
}

\begin{abstract}
Resumo - Este artigo analisa as concepções prevalentes acerca da relação das políticas sociais - direitos do trabalho, serviços de educação infantil e de cuidado aos idosos - com o trabalho remunerado e o trabalho do cuidado na família. Trata-se de um survey, com 1000 pessoas, amostral e probabilístico, desenvolvido no estado do Rio de Janeiro, entre os anos de 2013 e 2015. Prevalece uma percepção que atribui eminentemente às famílias o cuidado às crianças pequenas e aos idosos dependentes. Os resultados mostram que, para superar os ordenamentos de gênero, as políticas públicas direcionadas aos cuidados necessitam ser ampliadas e desmercantilizadas frente às desigualdades de gênero no mercado de trabalho e no interior das famílias, evidenciados pela pesquisa.

Palavras-chave: gênero; trabalho; família; políticas sociais; cuidados.
\end{abstract}

\begin{abstract}
This article analyzes the prevalent conceptions about the relationship of social policies - labor rights, early childhood services and care for the elderly - withpaid work and family care work. This is a sample and probabilistic survey with 1000 peoplein the state of Rio de Janeiro, between the years of 2013 and 2015. The prevailing perception assigns eminently to families the care of young children and dependent elderly people. The results show that, in order to overcome gender structures, public policies directed towards care need to be expanded and de-commodified, in face of gender inequalities in the labor market and within families, as evidenced by the survey.
\end{abstract}

Keywords: gender;work;family; social policies; care.

\footnotetext{
* Assistente Social. Doutora em Saúde Pública pela Escola Nacional de Saúde Pública ENSP-FIOCRUZ e Professora Adjunta da Faculdade de Serviço Social da Universidade do Estado do Rio de Janeiro (UERJ). Correspondência: Rua Professor Gastão Bahiana, 399/apt.103 - Lagoa - Rio de Janeiro - Brasil. CEP: 22.071-030. Email: <andreas gama@gmail.com>.

${ }^{*}$ Socióloga. Doutora em Sociologia pelo Instituto Universitário de Pesquisas do Rio de Janeiro (UERJ) e Professora Adjunta do Instituto de Ciências Sociais da UERJ. Correspondência: Rua São Francisco Xavier, 524/sl. 9033 Bloco A - Maracanã - Rio de Janeiro - Brasil. CEP: 20.559-900. Email: <liarocha08@gmail.com>.

${ }^{* * *}$ Socióloga. Mestre em Ciência Política pela Universidade Federal Fluminense. Assistente de Pesquisa do Núcleo de Estudos sobre Desigualdades Contemporâneas e Relações de Gênero (UERJ). Correspondência: Rua São Francisco Xavier, 524/sl. 9020 - Bloco A - Maracanã - Rio de Janeiro - Brasil. CEP: 20.559-900. Email: $<$ karolyneromero@gmail.com>.
} 


\section{Introdução}

Estudos recentes no Brasil vêm mostrando os conflitos decorrentes das mudanças nas configurações familiares associadas às transformações no mercado de trabalho, com destaque para a crescente e constante participação das mulheres nesse mercado (SORJ, 2004; ARAÚJO; SCALON, 2005; GAMA, 2014). Todas essas mudanças colocam em xeque a legitimidade do modelo tradicional de divisão sexual do trabalho, que reserva ao homem o espaço da produção econômica e à mulher os cuidados com a família. Ademais, e como consequência direta, introduz questões relacionadas à execução do trabalho reprodutivo na família.

A maior diferenciação dos arranjos familiares cria uma nova relação entre demanda e oferta de cuidados e, logo, necessidades e expectativas heterogêneas em relação ao Estado. Dentre essas novas expectativas temos o conflito entre trabalho e responsabilidades familiares, que engloba a equalização do trabalho doméstico, a educação das crianças, a atenção aos idosos - especialmente sob a perspectiva de maior longevidade e tamanhos menores de família - e o cuidado aos doentes e outros dependentes.

No Brasil, esse conflito não é percebido socialmente e com clareza política como decorrente dessas mudanças nas famílias e no mercado de trabalho, tendo como protagonistas as mulheres. As desigualdades sociais decorrentes desse conflito não são reconhecidas e, consequentemente, não são enfrentadas pelas políticas públicas. Na verdade, esse conflito é abordado apenas de maneira compartimentalizada, a partir das várias formas da sua expressão: como questões relacionadas à infância e à adolescência, ao enveIhecimento da população, à diminuição da fecundidade, à pauperização das famílias, todas afluentes do conflito entre trabalho e família, entre produção e reprodução social. Isso significa que o equacionamento desse conflito encontra dificuldade em se transformar em ação política, tanto decorrente do fato de que não se toma esse problema como sendo da esfera do trabalho e da família, como pela maneira fragmentada e difusa com que esse problema frequenta o "público": Estatuto da Criança e do Adolescente, Estatuto do Idoso, políticas de gênero, políticas direcionadas à pobreza das famílias, entre outras.

No entanto, as mudanças nas famílias não têm sido acompanhadas de alterações no papel do Estado no fornecimento de políticas públicas direcionadas a essas mudanças. Tal engessamento refere-se à concepção e desenho das políticas, bem como ao seu financiamento e provisão institucional. Os processos de reestruturação produtiva também apresentam impacto considerável, pois aumentam a insegurança das famílias em prover seu sustento, assim como colocam as mulheres em situação desfavorável pela sua maior proporção na informalidade e no subemprego. Ademais, o impacto do ideário neoliberal nas políticas sociais sobrecarrega ainda mais as famílias na responsabilização pelas necessidades da reprodução social. 
As taxas crescentes de emprego feminino no país se caracterizam, eminentemente, pela precariedade, e esse processo de integração das muIheres no mercado de trabalho se desenvolve de maneira muito desigual (BRUSCHINI; LOMBARDI, 2000). Sem dúvida, muitos fatores contribuem para gerar desigualdades entre as mulheres no mercado de trabalho, sobretudo diferenças de nível de escolarização. Todavia, estudos recentes que analisam a relação entre o trabalho feminino, políticas sociais e trabalho do cuidado, no Brasil, evidenciam que o processo desigual de inserção das mulheres ao mercado de trabalho tem relação com o acesso também desigual aos serviços de cuidado providos pelo Estado e mercado (LAVINAS; DAIN, 2005; CAMARANO, 2008; SORJ; FONTES, 2012; GAMA, 2014).

Em síntese, o que queremos dizer é que o mundo do trabalho mudou, e com ele as configurações e relações familiares também, mas o Estado mantém-se refratário às demandas decorrentes da reprodução social ensejadas pelo mundo do trabalho e pelas próprias famílias. Podemos visualizar tal afirmação pelo congelamento das mudanças no registro trabalhista para incorporar e dar conta das demandas de cuidado - não adesão da Convenção sobre Trabalhadores (as) com responsabilidades familiares da OIT, ausência de licença-parental, jornadas menores de trabalho sem redução de salário, entre outras. Do lado das políticas sociais, verifica-se a lenta ampliação dos serviços de Educação Infantil, principalmente, dos serviços de creche e do horário escolar em tempo integral, bem como a precária rede de cuidado aos idosos, mais centrada no déficit de renda do que no déficit crescente de cuidados, entre outros.

Esse cenário, mapeado por pesquisas acadêmicas e governamentais, não chegou a problematizar, no entanto, os valores e percepções da população sobre o papel que as políticas sociais podem ter no tocante ao conflito entre trabalho e responsabilidades familiares. Quais são as concepções prevalentes acerca das políticas sociais - direitos do trabalho, serviços de educação infantil e cuidado aos idosos - relacionadas ao trabalho remunerado e ao trabalho do cuidado na família? Quais são as instituições sociais que devem partilhar o cuidado às crianças pequenas e aos idosos? Há diferenças nessa percepção do papel das políticas de care quando o cuidado se refere às crianças pequenas e aos idosos dependentes? Há diferenças entre homens e mulheres, trabalhadores ou não, quanto à responsabilização pelo trabalho do cuidado? Qual a influência do trabalho e de ter filhos nas demandas de conciliação entre trabalho e responsabilidades familiares?

Esse estudo se propõe a analisar a percepção dos fluminenses acerca de questões que englobam os conflitos entre a vida familiar e a vida laboral. Ele foi dividido em três partes: na primeira, realizamos uma descrição da amostra/perfil dos respondentes. Na segunda parte, buscamos captar as percepções sobre os direitos do trabalho relativas às licenças remuneradas. Na terceira, identificamos as tendências na percepção sobre a organização 


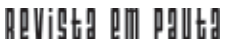

\} PERCEPCÕES SOBRE O PAPEL DAS POLITICAS PÚBLICAS - GAMA, A. S.; ROCHA, L. M.;ALCANTARA, K. R. \}

DOI $10.12957 /$ REP.2017.30379

e responsabilização pelo cuidado às crianças abaixo da idade escolar e aos idosos dependentes, bem como os encargos pela sustentação financeira dos cuidados a esses grupos. Investigamos essas questões a partir das seguintes características sociodemográficas: sexo, escolaridade, ocupação, situação na ocupação e renda individual.

\section{Caracterização socioeconômica dos entrevistados}

Caracterizamos a amostra a partir das seguintes variáveis socioeconômicas: escolaridade, composição da atividade, posição na ocupação, jornada de trabalho e número de horas de afazeres domésticos. Foram realizados testes de significância (Pearson chi-square) nas duas amostras, homens e mulheres, mas somente foram analisadas as correlações significativas. Quando o teste foi significativo para uma amostra apenas assinalamos em nota de rodapé.

Tabela 1 - Perfil da amostra

\begin{tabular}{|c|c|c|}
\hline & Homens & Mulheres \\
\hline \multicolumn{3}{|l|}{ Escolaridade } \\
\hline Sem instrução & $1.5 \%$ & $4.8 \%$ \\
\hline Ensino Fundamental completo & $38.8 \%$ & $40.1 \%$ \\
\hline Ensino Médio completo & $39.2 \%$ & $35.6 \%$ \\
\hline Ensino Superior completo & $13.6 \%$ & $16 \%$ \\
\hline Pós-graduação & $6.9 \%$ & $3.4 \%$ \\
\hline \multicolumn{3}{|c|}{ Composição da atividade } \\
\hline Ocupado(a) & $66.7 \%$ & $44.1 \%$ \\
\hline Desempregado(a) & $12.1 \%$ & $9.8 \%$ \\
\hline Inativo(a) & $23.6 \%$ & $51.6 \%$ \\
\hline \multicolumn{3}{|c|}{ Posição na ocupação } \\
\hline Empregado(a) & $52.7 \%$ & $36.8 \%$ \\
\hline Não estáempregado, mas tem trabalho & $14 \%$ & $7.3 \%$ \\
\hline Estáprocurando emprego & $9.3 \%$ & $4.3 \%$ \\
\hline Afazeres domésticos & $1.1 \%$ & $21.9 \%$ \\
\hline $\begin{array}{l}\text { Média de horas semanais de afazeres } \\
\text { domésticos }\end{array}$ & $10 \mathrm{~h}$ & $24 \mathrm{~h}$ \\
\hline Média semanal de horas trabalhadas & $46 \mathrm{~h}$ & $37 \mathrm{~h}$ \\
\hline
\end{tabular}




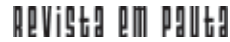

\} PERCEPÇÕES SOBRE O PAPEL DAS POLÍTICAS PÚBLICAS - GAMA, A. S.; ROCHA, L. M.;ALCANTARA, K. R. \} DOI $10.12957 /$ REP.2017.30379

Na população analisada, as taxas de ocupação dos homens são bem maiores do que das mulheres $-66.7 \%$ para eles e $44.1 \%$ para elas. Chama a atenção a elevada proporção de "se dedica aos afazeres domésticos"entre as mulheres, que perfaz $21.9 \%$.

A qualidade da inserção no mercado de trabalho pode ser medida pela sua posição na ocupação e pelo tipo de vínculo de trabalho que se estabelece, com e sem carteira de trabalho assinada. Entre os homens que trabalham, $8.2 \%$ estão no emprego público e $33.6 \%$ são assalariados do setor privado, totalizando $41.8 \%$ no emprego formal, e $23.9 \%$ trabalham por conta própria/autônomo. Dentre as mulheres que trabalham, 5.4\% encontram-se no emprego público e $21.3 \%$ são assalariadas do setor privado, totalizando $26.7 \%$ no emprego formal, e $16.4 \%$ trabalham por conta própria/ autônomo.

A renda individual mensal dos pesquisados, constituída por fontes como o salário, aposentadoria/pensões e benefícios sociais, concentra-se nos estratos mais baixos de renda. Há uma concentração na renda individual mensal em até três salários mínimos (SM): $64.3 \%$ dos homens e $68.7 \%$ das mulheres recebem até esse patamar. Verificamos também um alto percentual que se declarou sem renda: $11.4 \%$ para os homens e $19.8 \%$ para as mulheres. O rendimento mensal segue o padrão de desigualdade entre homens e muIheres.

Os dados ilustram o que vem sendo constatado por vários estudos: a manutenção da desigualdade de gênero no mercado de trabalho, expressa no nível de participação no mercado de trabalho, na formalidade do emprego e na distribuição do salário/renda. Sãodignos de nota, ainda, os elevados percentuais de "aposentado(a)/incapacitado(a) para o trabalho" e "se dedica aos afazeres domésticos" entre as mulheres.A baixa presença de filhos ou de crianças e adolescentes até17 anos nos domicílios chama a atenção nessa amostra, pois $63.4 \%$ deles não possuem nenhuma criança ou adolescente, $22 \%$ possuem até uma criança e $10.6 \%$ até duas crianças/adolescentes.

\section{Percepções sobre os Direitos do Trabalho}

As normas legais que guardam relação com a questão do conflito entre trabalho e responsabilidades familiares têm, nas licenças trabalhistas remuneradas, uma estratégia importante para a promoção da igualdade de gênero e enfrentamento da pobreza, a partir do mundo do trabalho.

Mesmo considerando a licença-maternidade abrangente, condicionada às condições de saúde da mulher, garantidora da integralidade e estabilidade do salário e do emprego, a proteção trabalhista brasileira, até hoje existente, apresenta muitas deficiências. Uma primeira ordem de carência é que a legislação trabalhista tende a centrar-se em demandas muito 


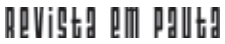

\} PERCEPÇÕES SOBRE O PAPEL DAS POLÍTICAS PÚBLICAS - GAMA, A. S.; ROCHA, L. M.;ALCANTARA, K. R. \}

DOI 10.12957/REP.2017.30379

específicas, relacionadas à gravidez e à maternidade, desconsiderando que as responsabilidades familiares se referem a homens e mulheres e que perpassam toda a vida laboral e familiar do (a) trabalhador (a), não restrita, portanto, àfase reprodutiva. Ademais, o discrepante tratamento legal dispensado às trabalhadoras-mães em relação aos trabalhadores-pais demonstra a natureza sexista no Direito do Trabalho brasileiro, que trata o cuidado da prole como de responsabilidade exclusiva da mulher, ignorando a participação do homem e reforçando o interesse estatal no controle da reprodução da força de trabalho.

Em segundo lugar, as formas de acesso aos benefícios e direitos do trabalho estão majoritariamente associadas ao vínculo empregatício e, portanto, restrita aos (as) trabalhadores (as) formais ou àqueles (as) que contribuem para a Previdência Social. Uma exclusão significativa é gerada em função disso, mediante a heterogeneidade e segmentação da força de trabalho no Brasil, em que a informalidade e o desemprego são as características mais evidentes.

Uma terceira deficiência se deve ao marcante viés de gênero dessa legislação por prover aos homens uma licença-paternidade de apenas cinco dias e a não regulamentação da licença-parental, instrumentos eficazes para o fomento à igualdade de gênero.

Consideramos essa pesquisa inovadora porque poucos estudos lançam luz sobre as percepções acerca desses direitos trabalhistas.

\subsection{Licença-paternidade}

Os atuais formatos de licença-maternidade e licença-paternidade reforçam a divisão sexual do trabalho. Nesse momento, pretendemos ponderar sobre as concepções dos respondentes quanto a essas licenças trabalhistas remuneradas. No entanto, buscamos problematizar, com destaque, a licença-paternidade, por ser este um direito pouco explorado nesse campo de estudos. Dessa forma, considerando as licenças já existentes e seu tempo de duração, perguntamos se eram favoráveis a uma licençapaternidade maior do que a existente e, se sim, de quanto tempo.

Agrupamos as variáveis em três grupos: manutenção do tempo da licença -"como está, 5 dias é suficiente"; ampliação do tempo de duração -"Sim, de dias" e "sim, de meses" e supressão do direito -"não deveria haver licença-paternidade remunerada".

Em relação àpergunta "O Sr(a). é a favor que exista uma licençapaternidade remunerada maior que a atual?" obtivemos a seguinte distribuição: 
\} PERCEPÇÕES SOBRE O PAPEL DAS POLÍTICAS PÚBLICAS - GAMA, A. S.; ROCHA, L. M.;ALCANTARA, K. R. \} DOI $10.12957 /$ REP.2017.30379

Tabela 2 - Distribuição das percepções

sobre a licença-paternidade remunerada*

\begin{tabular}{|c|c|c|c|}
\hline & Masculino & Feminino & Total \\
\hline Sim, de mais meses & $28.3 \%$ & $28.5 \%$ & $28.4 \%$ \\
\hline Sim, de mais dias & $23.1 \%$ & $19.1 \%$ & $20.9 \%$ \\
\hline Como está, 5 dias é o suficiente & $43.5 \%$ & $45.2 \%$ & $44.4 \%$ \\
\hline $\begin{array}{l}\text { Não deveria haver licença-paternidade } \\
\text { remunerada }\end{array}$ & $4 \%$ & $5.2 \%$ & $4.7 \%$ \\
\hline Não sabe/não respondeu & $1.1 \%$ & $2.1 \%$ & $1.7 \%$ \\
\hline Total & $100 \%$ & $100 \%$ & $100 \%$ \\
\hline $\mathrm{N}$ & 527 & 671 & 1198 \\
\hline
\end{tabular}

$*($ Pearson chi-quadrado $=, 278)$

Observamos inicialmente que as respostas de homens e mulheres são bastante próximas e a maioria dos entrevistados (44.4\%) respondeu que considera a licença-paternidade atual de cinco dias suficiente. Entre aqueles que responderam que concordavam com a ampliação do período de gozo da licença-paternidade (LP), os homens totalizavam $51.4 \%$, e as mulheres, $47.6 \%$.

Poderíamos, inicialmente, considerar surpreendente o fato de os homens responderem de maneira mais afirmativa que a licença-paternidade deve ser modificada no sentido da sua ampliação. Isso significa que uma parcela considerável das mulheres mantém uma percepção de que os cuidados iniciais com os filhos são fundamentalmente sua atribuição, com reduzida relevância uma maior participação dos pais nesse período. Sabese que, culturalmente, no Brasil, os cuidados pós-parto e com o bebêsão um espaço muito feminino (FONSECA, 2002). Logo, se é a mulher que tem maior carga de trabalho de cuidado com os bebês, o pai não necessita se afastar do trabalho por esse motivo.

Entretanto, percebe-se uma nova demanda social por direitos relacionada àmaior participação masculina na família. Podemos ilustrar esse movimento na incidência de projetos de lei tramitando nas instâncias legislativas, que visam a mudanças na atual configuração da licença-paternidade. Nos últimos cinco anos, por exemplo, foram apresentados 15 projetos de lei no Congresso Nacional direcionados à ampliação da licença-paternidade, $2 / 3$ destes por parlamentares do sexo masculino. No entanto, o viés maternalista permanece predominante nas justificativas dos projetos.

Quando examinados a partir do nível educacional, observou-se que - para ambos os sexos -,com o aumento da escolaridade, a opção 


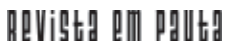

\} PERCEPÇÕES SOBRE O PAPEL DAS POLÍTICAS PÚBLICAS - GAMA, A. S.; ROCHA, L. M.;ALCANTARA, K. R. \}

DOI 10.12957/REP.2017.30379

favorável ao aumento do tempo da licença-paternidade tornou-se mais frequente.

No que tange àocupação, estar ativo economicamente teve correlação positiva com ser favorável ao aumento da licença-paternidade, tanto para homens, quanto para mulheres.

Não foi possível destacar a influência da variável posição na ocupação e renda individual em termos de ser favorável ou não ao aumento da licença-paternidade. Cabe destacar a extrema concentração da amostra nos extratos mais baixos da distribuição (até cinco SM), dificultando a análise das diferenças.

\subsection{Divisão do tempo de licença remunerada entre homens e mulheres}

Em relação àpergunta:"Se ambos estão empregados e são elegíveis a receber licença remunerada, como deveria ser dividido o período da licença entre a mãe e o pai?", obtivemos a seguinte distribuição:

Tabela 3 -Distribuição das percepções sobre a elegibilidade da licença remunerada***

\begin{tabular}{|c|c|c|c|}
\hline & Masculino & Feminino & Total \\
\hline Sim, de mais meses & $28.3 \%$ & $28.5 \%$ & $28.4 \%$ \\
\hline Sim, de mais dias & $23.1 \%$ & $19.1 \%$ & $20.9 \%$ \\
\hline Como está, 5 dias é o suficiente & $43.5 \%$ & $45.2 \%$ & $44.4 \%$ \\
\hline $\begin{array}{c}\text { Não deveria haver licença-paternidade } \\
\text { remunerada }\end{array}$ & $4 \%$ & $5.2 \%$ & $4.7 \%$ \\
\hline Não sabe/não respondeu & $1.1 \%$ & $2.1 \%$ & $1.7 \%$ \\
\hline Total & $100 \%$ & $100 \%$ & $100 \%$ \\
\hline $\mathrm{N}$ & 527 & 671 & 1198 \\
\hline
\end{tabular}

*Significativo (Pearson chi-square $=, 000$ )

** A opção "O pai deveria tirar todo o período da licença remunerada e a mãe não deveria ter tempo algum"não teve nenhuma resposta.

Consideramos que as opções "a mãe deveria tirar todo o período da licença remunerada e o pai não deveria ter direito à licença" e "a mãe deveria tirar a maior parte do período da licença remunerada e o pai apenas uma parte dela" são respostas que ilustram o papel da mulher como a principal responsável pelo cuidado das crianças. Essas foram as opções mais frequentemente escolhidas pelos entrevistados. Somados, os valores chegam a $80.3 \%$ entre os homens e $80 \%$ entre as mulheres ( $80.2 \%$ na amostra geral). 
As opções favoráveis à divisão mais igualitária do cuidado das crianças entre homens e mulheres, no caso,"a mãe e o pai deveriam, cada um, ter uma metade do período da licença remunerada" e "o tempo de licença deveria ser negociado entre o casal e distribuído por eles" foram escolhidas por aproximadamente $8 \%$ da amostra.

Ademais, vale a pena destacar que mais frequentemente as muIheres responderam que elas deveriam ser as únicas com direito à licença remunerada para o cuidado das crianças pequenas, comparando com os homens. As escolhas mencionadas parecem indicar dois dados relevantes: o primeiro diz respeito a uma posição masculina que tende mais à manutenção da licença com o gozo maior da mesma pelas mulheres, do que à posição feminina mais conservadora no tocante a uma licença remunerada exclusivamente de direito das mulheres. Revela, ainda, o forte traço maternalista presente entre as mulheres no cuidado aos recém-natos. Também é necessário considerar o fato de que grande parte das informantes está fora do mercado de trabalho, o que certamente influencia nessas percepções.

Podemos afirmar que a extensa maioria da amostra declarou considerar papel da mãe o cuidado com as crianças pequenas, de modo que ela deve usufruir da maior parte da licença remunerada para tal finalidade. Não foi possível observar diferenças significativas por anos de escolaridade, inserção no mercado de trabalho, posição na ocupação e faixa de renda. Além disso, as respostas entre homens e mulheres não se diferenciaram de forma evidente.

Conforme a Tabela 3, encontramos a maior frequência de resposta na ampliação do período da LP. As mulheres que mais demandaram a ampliação do tempo de duração da LP foram as que "têm filho e não trabalham" $(61.4 \%)$. Esse grupo, inclusive, tem a maior proporção que considera a necessidade de aumento desse período em meses (35.6\%). Esse resultado, que indica uma opinião mais favorável ao aumento da LP quando na presença de filhos, sugere a influência da maternidade na inserção no mercado de trabalho. Os homens que mais demandaram a ampliação da LP foram muito semelhantes entre o grupo que "não tem filho e trabalha" (56.4\%), seguido dos que "têm filho e trabalham" (55.1\%), com proporções muito próximas em termos do tempo a ser ampliado, seja em dias ou meses.

Diferentemente das mulheres, a inserção no mercado de trabalho, para os homens, influenciou de forma mais marcante a sua percepção de que a LP deve ser aumentada. Isso pode indicar que os homens que trabalham percebem mais a importância desse direito trabalhista na possibilidade de exercício da paternidade. Na verdade, a inserção no trabalho foi o fator de maior influência em uma visão mais progressista, tanto para os homens como para as mulheres.

Esses resultados mostram a permanência de um traço maternalista no entendimento dos entrevistados, pois expressa exatamente o que está previsto na legislação trabalhista brasileira. Ou seja, o traço maternalista 


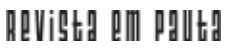

\} PERCEPÇÕES SOBRE O PAPEL DAS POLÍTICAS PÚBLICAS - GAMA, A. S.; ROCHA, L. M.;ALCANTARA, K. R. \}

DOI 10.12957/REP.2017.30379

está presente na política pública, bem como na percepção dos sujeitos de direitos. No entanto, compreende-se o surgimento de visões diferenciadas no tocante à divisão do tempo das licenças remuneradas. Essas percepções podem indicar mudanças de valores em direção a uma perspectiva mais igualitária se coadunadas com as mudanças na legislação, que podem induzir e reforçar novas ideias e práticas sobre o tema.

\subsection{Divisão do tempo do cuidado com as crianças e o trabalho entre homens e mulheres}

A pergunta sobre esse item foi assim formulada: "Considere um casal com criança abaixo da idade escolar. Qual, em sua opinião, seria a melhor maneira para eles organizarem o cuidado da criança na família?". As possibilidades de resposta estão na tabela abaixo.

Tabela 4 - Distribuição das percepções sobre a divisão do tempo de cuidado com as crianças***

\begin{tabular}{|c|c|c|c|}
\hline & Masculino & Feminino & Total \\
\hline Sim, de mais meses & $28.3 \%$ & $28.5 \%$ & $28.4 \%$ \\
\hline Sim, de mais dias & $23.1 \%$ & $19.1 \%$ & $20.9 \%$ \\
\hline Como está, 5 dias é o suficiente & $43.5 \%$ & $45.2 \%$ & $44.4 \%$ \\
\hline $\begin{array}{l}\text { Não deveria haver licença-paternidade } \\
\text { remunerada }\end{array}$ & $4 \%$ & $5.2 \%$ & $4.7 \%$ \\
\hline Não sabe/não respondeu & $1.1 \%$ & $2.1 \%$ & $1.7 \%$ \\
\hline Total & $100 \%$ & $100 \%$ & $100 \%$ \\
\hline $\mathrm{N}$ & 527 & 671 & 1198 \\
\hline
\end{tabular}

$*$ (Pearson chi-quadrado $=, 064)$

**As opções "O pai fica em casa e a mãe trabalha em tempo integral" e "O pai trabalha meio expediente e a mãe trabalha em tempo integral"não obtiveram nenhuma resposta

Trabalhamos juntas as respostas que expressam as concepções mais tradicionais de responsabilidade entre os sexos. Ou seja, tanto aqueles que responderam que a melhor condição para o cuidado da criança é a mãe ficar em casa e o pai trabalhar em tempo integral, quanto aqueles que responderam que a mãe deveria trabalhar meio expediente e o pai em tempo integral, quer dizer, aqueles que compreendem como responsabilidade materna o cuidado com a criança. Nesse sentido, temos novamente uma concentração da amostra: $81 \%$ escolheram uma das duas opções mencionadas, sendo $80.7 \%$ entre os homens e $81.6 \%$ entre as mulheres. 


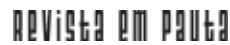

\} PERCEPÇÕES SOBRE O PAPEL DAS POLÍTICAS PÚBLICAS - GAMA, A. S.; ROCHA, L. M.;ALCANTARA, K. R. \} DOI $10.12957 /$ REP.2017.30379

Considerando a escolaridade ${ }^{1}$ dos entrevistados, entre os homens observamos uma correlação entre os mais escolarizados da amostra (Superior incompleto ou mais) e uma visão menos tradicional sobre essa divisão. Entre as mulheres, contudo, o mesmo padrão não foi observado.

Nos cruzamentos da pergunta sobre a divisão do tempo da licença remunerada com a ocupação dos entrevistados, novamente, não foi observada uma distribuição distinta entre aqueles ativos e inativos economicamente, para ambos os sexos. Também não foi encontrada relação entre o aumento da renda e uma percepção menos tradicional sobre a organização do cuidado às crianças, para ambos os sexos.

É interessante observar que a pergunta sobre o aumento da licençapaternidade tenha tido respostas menos conservadoras do que as que comparam as responsabilidades no cuidado com as crianças entre homens e mulheres. Parece indicar que émais aceitável a extensão do tempo de licença para os homens, desde que isso não modifique o lugar central da mulher na função do cuidado.

A aceitação hegemônica da ideia de cuidado às crianças pequenas na família, em contraposição ao trabalho remunerado das mães, se coaduna aos diversos estudos que evidenciam o peso diferenciado da maternidade e da paternidade sobre as condições e perspectivas de trabalho de homens e mulheres. As dificuldades de acesso aos equipamentos públicos de cuidado infantil também contribuem para essa concordância, além dos altos índices de mulheres dedicadas aos afazeres domésticos e a baixa taxa de participação feminina no mercado de trabalho encontrado na amostra.

No entanto, verificamos que o fato de homens e mulheres trabaIharem fora influencia uma concepção menos tradicional quanto às tentativas de conciliação entre trabalho remunerado e cuidado às crianças pequenas. Na resposta "a mãe trabalha meio expediente e o pai trabalha em tempo integral", que foi a segunda mais prevalente, as mulheres trabalhadoras escoIheram mais essa opção do que as não trabalham.

Com relação às que possuem filhos, $40 \%$ afirmam que essa é a melhor opção de compatibilização, enquanto que aquelas que não têm fiIhos totalizam $34.8 \%$. No caso dos homens, mais frequentemente optaram por esse padrão os que têm filhos e trabalham (28\%), seguido daqueles que têm filhos e não trabalham (27.8\%). Essas respostas nos sugerem que o trabalho remunerado das mulheres éum fator fundamental para o sustento das famílias, principalmente quando na presença de filhos, e se constitui como um aspecto de maior penetração de representações menos conservadoras. No entanto, o cuidado às crianças pequenas ainda permanece como um espaço prioritário das mulheres. Tal percepção acompanha o seu lugar tradicional no cuidado em detrimento da sua inserção no mercado de trabalho.

${ }^{1}$ Os cruzamentos da pergunta com a escolaridade dos entrevistados foram significativas somente para os homens (Pearson chi-quadrado $=, 000)$. 
\} PERCEPÇÕES SOBRE O PAPEL DAS POLÍTICAS PÚBLICAS - GAMA, A. S.; ROCHA, L. M.;ALCANTARA, K. R. \} DOI $10.12957 /$ REP.2017.30379

\section{Cuidados, cuidadores e financiamento da proteção social às crianças pequenas e idosos dependentes}

Uma das questões básicas para qualquer arquitetura do bem-estar é saber como alocar a sua produção entre mercado, Estado e família. Apesar da inexistência de uma concepção unívoca de direitos sociais quanto aos distintos papéis atribuídos a cada um desses pilares, a crítica feminista vai incidir com contundência sobre o papel das mulheres nessa provisão, através do trabalho do cuidado não remunerado exercido na esfera da família.

Analistas feministas defendem a introdução do "cuidado"como central na definição dos modelos de Estado de Bem-Estar Social. Elas propõem, nessas análises, uma tipologia do Welfare State, organizando-os a partir de regimes de cuidado. Isso significa analisar a distribuição de provisão entre as esferas do mercado, da família e do Estado, bem como os serviços, as transferências em dinheiro, de bens e de tempo proporcionados pelas distintas esferas (JENSON, 1997; LEWIS, 2001; O'CONNOR; ORLOFF; SHAVER, 1999).

A principal pergunta a que essas analistas se colocam é: quais as consequências de um regime de cuidado para a equidade de gênero? Elas argumentam que esses aspectos são obscurecidos pela ausência de um diagnóstico coerente dos custos diferenciados do cuidado dos dependentes para as famílias, Estado e mercado. Por exemplo, as análises econômicas convencionais consideram elevados os gastos sociais com os idosos pelo Estado, mas nunca se preocupam em comparar esses custos com os realizados pelas famílias. Isso se deve, em grande parte, à suposição implícita de que as famílias, especialmente as mulheres, provêm serviços sociais gratuitos.

Desse modo, apresentam dois modelos dos regimes de cuidado: o familista e o desfamilizador. No regime familista, a responsabilidade principal do bem-estar estáa cargo das famílias e das mulheres nas redes de parentesco. Mesmo que as mulheres trabalhem de forma remunerada, são elas, eminentemente, que irão desenvolver estratégias para articular trabalho e família. No regime desfamilizador há uma divisão entre as instituições públicas e o mercado. Esses processos de desfamilização são muito variados e possuem ritmos diferenciados historicamente e mediante a realidade dos países. Entra em jogo, portanto, o peso das políticas públicas, a extensão dos serviços privados e o papel das famílias e das redes informais (SARACENO, 1995; KNIJN; UNGERSON, 1997; SAINSBURY, 2001).

No caso brasileiro, identificar um padrão institucional tende a obscurecer as fortes desigualdades sociais que afetam o acesso diferencial àprovisão de serviços prestados pelo Estado, mercado e família. Em termos gerais, o Brasil caracteriza-se pela ainda forte presença da economia informal e por seu frágil Estado de Bem-Estar Social. Trata-se de um caso de "provedor desigual", ou"mix"de um regime meritocrático e assistencial protegendo via sistema previdenciário aqueles que se encontram empregados no 
mercado formal, com uma crescente privatização seletiva da política de saúde e uma política de assistência social inflada, que vem apresentando resultados relevantes em termos da diminuição da pobreza. O ligamento desse padrão de bem-estar, entretanto, baseia-se no papel atribuído àfamília, especialmente às mulheres, na oferta de serviços de cuidados não pagos e não reconhecidos.

Nesse momento, buscaremos identificar algumas tendências na percepção sobre as instituições sociais que devem se responsabilizar pelo cuidado às crianças abaixo da idade escolar e aos idosos dependentes, bem como pela sustentação financeira dos cuidados a esses grupos.

\subsection{Cuidados e responsabilidades com as crianças pequenas}

Em relação à pergunta "As pessoas têm diferentes opiniões sobre quem deveria cuidar de crianças abaixo da idade escolar, ou seja, sobre como as responsabilidades de cuidado deveriam ser preferencialmente distribuídas. Qual dessas alternativas mais se aproxima do que o(a) Sr(a). pensa?", obtivemos a seguinte distribuição:

Tabela 5 - Distribuição das percepções acerca da divisão das responsabilidadescom o cuidado das crianças abaixo da idade escolar*

\begin{tabular}{|c|c|c|c|}
\hline & Masculino & Feminino & Total \\
\hline Familiares & $62.9 \%$ & $67.7 \%$ & $65.6 \%$ \\
\hline Creches públicas e instituições do governo & $28.5 \%$ & $21.7 \%$ & $24.7 \%$ \\
\hline $\begin{array}{c}\text { Organizaçōes sem fins lucrativos (ex.zorganizaçōes de caridade, } \\
\text { igrejas etc.) }\end{array}$ & $0.2 \%$ & $0.0 \%$ & $0.1 \%$ \\
\hline Serviços e instituiçōes privadas (ex.: creches particulares, babás etc.) & $4.8 \%$ & $3.6 \%$ & $4.1 \%$ \\
\hline Empregadores (empresas nas quais pai ou mãe trabalham) & $2.9 \%$ & $6.5 \%$ & $4.9 \%$ \\
\hline NS/NR & $0.8 \%$ & $0.4 \%$ & $0.6 \%$ \\
\hline Total & $100 \%$ & $100 \%$ & $100 \%$ \\
\hline $\mathrm{N}$ & 526 & 672 & 1198 \\
\hline
\end{tabular}

$*($ Pearson chi-quadrado $=, 004)$

Em torno de $65.6 \%$ de todos os entrevistados consideram que é a família o principal ente responsável pelo cuidado das crianças abaixo da idade escolar (seis anos).

Entre os homens, $62,9 \%$ responderam que quem deve cuidar das crianças é a família, e, para as mulheres, essa proporção foi de $67.7 \%$. Entre os que responderam que quem deve cuidar, preferencialmente, são as "cre- 


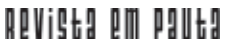

\} PERCEPÇÕES SOBRE O PAPEL DAS POLÍTICAS PÚBLICAS - GAMA, A. S.; ROCHA, L. M.;ALCANTARA, K. R. \}

DOI 10.12957/REP.2017.30379

ches públicas e/ou instituições do governo", 28.5\% eram homens e 21.7\% mulheres. As demais opções, que correspondem a "serviços e instituições privadas" ou "responsabilidade dos empregadores", totalizaram $8.6 \%$ entre os homens e $10.2 \%$ entre as mulheres. As mulheres elegeram com mais frequência a opção "responsabilidade dos empregadores". Tal informação pode ser um indicativo da tentativa feminina de minimizar o "ônus da maternidade", conciliando a vida laboral com a responsabilidade pelo cuidado infantil com a existência de creches nas empresas.

Encontramos uma oscilação nas frequências das respostas, segundo os níveis de escolaridade. No entanto, observa-se uma tendência de diminuição da família como a principal responsável pelos cuidados às crianças pequenas conforme aumenta o nível de escolaridade. Ou seja, com o aumento da escolaridade, principalmente a partir do Ensino Superior completo, os entrevistados acionam outras opções de cuidado.

Com relação à inserção no mercado de trabalho constatamos que estar ativo neste mercado diminui o papel tradicional de gênero, que atribui somente às famílias esse cuidado, sobretudo entre as mulheres. Dentre as mulheres que não trabalham, aproximadamente $75 \%$ consideram que é a família a responsável pelo cuidado, enquanto que entre as que trabalham essa proporção cai para $60 \%$.

Em relação à posição na ocupação², os homens que mais responderam que era a família a principal responsável pelo cuidado foram os "assalariados do setor privado" com $66.9 \%$ entre as mulheres, foram as que "trabalham por conta própria/autônomo", $72.5 \%$. Podemos inferir que as mulheres que exercem a amplitude desse tipo de atividade têm maiores possibilidades de conciliar o trabalho e o cuidado em função de uma possível flexibilidade no horário de trabalho e, portanto, atribuem a si mesmas o papel tradicional de gênero de cuidadora.

Os homens que mais responderam "creches públicas e instituições do governo" foram os que "trabalham por conta própria/autônomo", com $31.5 \%$. Dentre as trabalhadoras que afirmaram serem as "creches públicas e instituições do governo" os responsáveis pelos cuidados com as crianças pequenas, $27.1 \%$ afirmaram que "não estão empregadas neste momento, mas têm trabalho". Ambas as posições na ocupação, que se constituem como as atividades mais informalizadas, evidenciam a necessidade de compartilhamento dos cuidados com as instituições públicas.

Ainda entre as mulheres, destacamos que $11.9 \%$ das "assalariadas do setor privado" responderam que eram os"empregadores" os responsáveis e $16.7 \%$ das "assalariadas do governo" responderam"serviços e instituições privadas". Essas proporções ficam acima das médias gerais de resposta a essa pergunta e ilustram, no primeiro caso, a demanda das trabalhadoras do setor privado por esse direito trabalhista, e, no segundo, a compra de

${ }^{2} \mathrm{~A}$ amostra em relação à posição na ocupação foi significativa somente para os homens (homens Pearson chiquadrado) 
serviços no mercado devido àexistência de benefícios em dinheiro recebidos pelas servidoras públicas.

Observando a distribuição das respostas a partir da renda individual, em relação aos homens, aqueles que responderam a família encontram-se nos pontos opostos da distribuição de renda, entre "os sem renda" e "até 1 SM" (67\%), e aqueles que recebem "mais de 10 a 15 SM" (100\%). Em virtude da ausência ou baixíssima renda, a família, nesse caso, será a única possibilidade de cuidado, enquanto que aqueles com rendas elevadas podem garantir o cuidado no interior da família via empregadas domésticas.

Os homens que responderam "creches públicas e instituições do governo"concentram-se entre os que recebem de um a cinco SM (30\%). As mulheres que responderam "familiares" totalizam $72.2 \%$ entre as que recebem até um SM. Entre as que responderam "creches públicas e instituições do governo", $30 \%$ da amostra ganha"mais de 1 até 2 SM" (30\%). Dentre as que responderam "serviços e instituições privadas", $28.6 \%$ recebem "mais de 5 até10 SM". Para as que responderam "responsabilidade dos empregadores", $18.9 \%$ recebiam "mais de 3 até 5 SM".

Esses resultados parecem indicar que, em geral, as outras opções de cuidado infantil à família são acionados com mais frequência entre aquelas que possuem rendas maiores. Entre os homens, o resultado não foi significativo estatisticamente.

\subsection{Responsabilidades pelos custos com as crianças}

Em relação a pergunta "quem deveria, preferencialmente, cobrir os custos financeiros dos cuidados com as crianças, obtivemos a distribuição conforme a tabela 6 .

Em torno de $71.6 \%$ dos respondentes consideram que quem deve cobrir os custos financeiros desse cuidado é a família. "Estado/governo" totalizam $21.1 \%$, e a última categoria aparece com números residuais: $4.2 \%$ responderam que esses custos são de responsabilidade do "empregador".

De modo geral, os dados referentes à escolaridade não apresentam isoladamente um padrão explicativo.

Os homens trabalhadores $(80 \%)$ tendem a creditar mais à família a responsabilidade pelos custos dos cuidados com as crianças do que as mulheres trabalhadoras $(68 \%)$. As mulheres optam, com mais frequência, pela responsabilização do custeio pelo Estado (24\%) do que os homens (15\%). Entre aquelas que não estão ocupadas, a situação parece se inverter: as mulheres afirmam, com mais frequência que os homens, que a família deve ser a principal responsável pelo custeio dos cuidados com as crianças pequenas $(75 \%$ x 58\%). Tal opinião pode ser influenciada pelo fato de não trabalharem e estarem quase totalmente envolvidas na provisão dos cuidados na família. 
\} PERCEPCÕES SOBRE O PAPEL DAS POLÍTICAS PÚBLICAS - GAMA, A. S.; ROCHA, L. M.;ALCANTARA, K. R. \} DOI $10.12957 /$ REP.2017.30379

Tabela 6 - Quem deveria cobrir os custos financeiros dos cuidados com as crianças abaixo da idade escolar*

\begin{tabular}{|c|c|c|c|}
\hline & Masculino & Feminino & Total \\
\hline A familia & $70.8 \%$ & $72.3 \%$ & $71.6 \%$ \\
\hline O Estado/governo & $21.8 \%$ & $20.6 \%$ & $21.1 \%$ \\
\hline $\begin{array}{c}\text { Empregador (empresas nas quais pai ou mãe } \\
\text { trabalham) }\end{array}$ & $4.4 \%$ & $4.0 \%$ & $4.2 \%$ \\
\hline Outras & $1.7 \%$ & $0.9 \%$ & $1.3 \%$ \\
\hline NS/NR & $1.3 \%$ & $2.2 \%$ & $1.8 \%$ \\
\hline Total & $100 \%$ & $100 \%$ & $100 \%$ \\
\hline $\mathrm{N}$ & 527 & 671 & 1198 \\
\hline
\end{tabular}

*Não significativo (Pearson chi-quadrado $=, 512$ )

No que se refere à posição na ocupação ${ }^{3}$, homens e mulheres" assalariados do governo" e do"setor privado" foram os mais preponderantes em considerar a família como a principal provedora financeira dos cuidados às crianças pequenas (76.5\% em média). Em ambos os casos, os que trabalham por "conta própria/autônomos" escolheram com mais frequência a opção instituições públicas (ainda que a opção família tenha sido a preponderante), $20.6 \%$ para os homens e $22 \%$ para as mulheres. A estabilidade do setor público e os maiores salários nesse segmento profissional e na iniciativa privada, se comparado àqueles que trabalham por conta própria/autônomos, podem explicar a necessidade de maior suporte público no financiamento desses cuidados.

Não encontramos uma correlação direta entre a renda dos indivíduos e a percepção sobre o financiamento dos cuidados.

\subsection{Cuidados e responsabilidades com os idosos dependentes}

Buscamos conhecer as concepções em termos do trabalho do cuidado aos idosos dependentes e o papel desempenhado pelas outras instâncias de proteção social. Em média, 86\% dos informantes consideram que é a família que deve se responsabilizar pelos cuidados aos idosos dependentes. Essa média ésuperior àquela encontrada para a responsabilização pelo cuidado às crianças pequenas (66\%). Tal diferença sinaliza uma maior obrigação da família no cuidado aos idosos com encurtado espaço de compartilhamento com o Estado e o mercado. Isso pode ser explicado pela reduzida oferta e utilização de serviços/instituições públicas e privadas

${ }^{3}$ A amostra foi significativa somente para os homens (homens Pearson chi-quadrado $=, 001$ ). 
\} PERCEPÇÕES SOBRE O PAPEL DAS POLÍTICAS PÚBLICAS - GAMA, A. S.; ROCHA, L. M.;ALCANTARA, K. R. \} DOI $10.12957 /$ REP.2017.30379

direcionadas aos idosos com limitações, se comparado com os serviços de cuidado infantil, sejam eles públicos ou privados, no Brasil.

Para a pergunta "Pensando nos idosos que precisam de alguma ajuda ou têm problemas de saúde que limitam sua autonomia para realizar as atividades em seu dia a dia, como ajuda com compras no mercado, com a limpeza da casa etc., quem, em sua opinião, deveria preferencialmente se responsabilizar por esse tipo de ajuda?"obtivemos a seguinte distribuição:

Tabela 7 - Distribuição das percepções sobre a responsabilidade em relação aos cuidados com os idosos dependentes*

\begin{tabular}{|c|c|c|c|}
\hline & Masculino & Feminino & \multicolumn{1}{c|}{ Total } \\
\hline Familiares & $83.3 \%$ & $87.9 \%$ & $85.9 \%$ \\
\hline Instituições do governo apropriadas para esses serviços & $12.1 \%$ & $10.4 \%$ & $11.2 \%$ \\
\hline $\begin{array}{c}\text { Organizaçōes sem fins lucrativos (ex.: organizações de } \\
\text { caridade, igrejas/organizações }\end{array}$ & $0,6 \%$ & $0,7 \%$ & $0,7 \%$ \\
\hline Empresas privadas que fornecem esse tipo de cuidado & $1,3 \%$ & $0,6 \%$ & $0,9 \%$ \\
\hline Outros & $1,5 \%$ & $0,0 \%$ & $0,7 \%$ \\
\hline NS/NR & $1,1 \%$ & $0,3 \%$ & $0,7 \%$ \\
\hline Total & $100 \%$ & $100 \%$ & $100 \%$ \\
\hline N & 527 & 671 & 1198 \\
\hline
\end{tabular}

$*($ Pearson chi-quadrado $=, 005)$

Através da escolaridade e da posição na ocupação não foi possível, isoladamente, observar um padrão significativo entre as percepções dos respondentes.

Em relação à ocupação, o cruzamento foi significativo apenas para os homens. Entre esses, os ocupados ${ }^{4}$ referem-se ligeiramente menos $(80 \%)$ do que os não ocupados $(88 \%)$ à família como a fonte primeira de cuidados aos idosos dependentes. Não encontramos diferenças percentuais entre ocupados e não ocupados na opção "instituições do governo".

No que se refere à renda individual ${ }^{5}$, o cruzamento foi significativo apenas para os homens. Assim, 95\% dos homens que ganham entre cinco e 15 SM responderam "familiares", o que representa um acréscimo percentual expressivo em relação à média geral de respostas na categoria "familiares" (85\%). Na categoria "instituições do governo", destaque para aqueles que

\footnotetext{
${ }^{4}$ Os cruzamentos da pergunta foram significativos somente para os homens (homens Pearson chi-quadrado = ,000).

${ }^{5}$ Os cruzamentos da pergunta foram significativos somente para os homens (homens Pearson chi-quadrado = ,001 e mulheres Pearson chi-quadrado $=, 371$ ).
} 
\} PERCEPÇÕES SOBRE O PAPEL DAS POLÍTICAS PÚBLICAS - GAMA, A. S.; ROCHA, L. M.;ALCANTARA, K. R. \}

DOI $10.12957 /$ REP.2017.30379

recebem menos ("mais de 2 até3 $S M$ "), com 22,9\% das respostas desse grupo nessa categoria.

\subsection{Responsabilidades pelos custos com os idosos dependentes}

Na pergunta "Quem deveria, preferencialmente, cobrir os custos financeiros dos cuidados com esses idosos?", obtivemos a seguinte distribuição:

Tabela 8 - Distribuição das percepções sobre a responsabilidade com os custos financeiros dos cuidados com idosos dependentes*

\begin{tabular}{|c|c|c|c|}
\hline & Masculino & \multicolumn{1}{c|}{ Feminino } & Total \\
\hline Os próprios idosos e suas famílias & $54.1 \%$ & $58.5 \%$ & $56.5 \%$ \\
\hline O Estado/governo ou fundos públicos & $41.4 \%$ & $37.8 \%$ & $39.4 \%$ \\
\hline Outros & $1.9 \%$ & $0.1 \%$ & $0.9 \%$ \\
\hline NS/NR & $2.7 \%$ & $3.6 \%$ & $3.2 \%$ \\
\hline Total & $100 \%$ & $100 \%$ & $100 \%$ \\
\hline N & 527 & 672 & 1199 \\
\hline
\end{tabular}

* (Pearson chi-quadrado $=, 006)$

Quando perguntados sobre quem deveria, preferencialmente, se responsabilizar pelos custos com os idosos, 56.5\% dos entrevistados responderam que os custos devem ser de responsabilidade dos"próprios idosos e suas famílias", enquanto que para o financiamento dos cuidados às crianças foram $71.6 \%$. Isso significa que os entrevistados consideram que esse custo deve ser mais compartilhado com outras instituições sociais, pois 39.5\% responderam que, preferencialmente, esses custos devem ser de responsabilidade do "Estado/governo ou fundos públicos".

Esse dado chama a atenção na medida em que, tendo em vista todo o bloco de questões voltadas para a divisão dos cuidados aos idosos, a família aparece como a principal fonte de cuidados. Entretanto, quando se refere aos suportes financeiros desse cuidado, constatamos uma maior aceitação da divisão desses custos com o Estado, especificamente.

Tomando em conta o grau de escolaridade ${ }^{6}$, para ambos os sexos, os mais instruídos responderam que esse custo é de responsabilidade dos "próprios idosos e suas famílias", em média $66 \%$ entre os homens que possuem "até Ensino Superior completo" e"Pós-Graduação", e 69\% entre as mulheres. Encontramos a maior incidência dos que atribuem a responsa-

${ }^{6}$ Os cruzamentos da pergunta foram significativos somente para os homens (Pearson chi-quadrado $=007$ ). 
bilidade ao "Estado/governo" entre aqueles com menor escolaridade, ou seja, 39\% dos que possuem "até Ensino Fundamental completo".

Entre os ocupados ${ }^{7}$, em média $60 \%$ dos homens e $54 \%$ das mulheres responderam que os custos pelos cuidados devem ser de responsabilidade dos "próprios idosos e suas famílias", e 23\% responderam que é do"Estado/ governo". Dentre os não ocupados, independente do sexo, $54 \%$ consideram que os custos devem ser das "famílias" e $42 \%$, que a responsabilidade financeira deve ser do "Estado/governo".

Observando os dados comparativamente entre homens e mulheres, os homens apresentam uma percepção mais tradicional em relação à responsabilização com os custos dos cuidados com os idosos do que as muIheres. No entanto, a divisão das responsabilidades com o financiamento dos cuidados ainda é mais bem aceita em relação aos idosos do que em relação às crianças.

Não encontramos diferenças na situação de ocupação na relação com as percepções de ambos os sexos acerca da responsabilização pelos custos com os idosos, seja pelas famílias ou pelo Estado. As distribuições das opiniões nas categorias de ocupação são muito próximas entre si e da média geral.

No que se refere à renda ${ }^{8}$, para ambos os sexos, aqueles que possuem renda mais alta foram os que mais responderam que os "próprios idosos e suas famílias" são os responsáveis pelos custos dos cuidados, enquanto que os de menor renda reportam o "Estado/governo"como o principal provedor financeiro dos cuidados.

Diferentemente do financiamento do cuidado às crianças, háuma maior aceitação (38.2\%) no compartilhamento dos gastos do cuidado aos idosos dependentes com as instituições públicas. Aqui, o mercado não aparece, seja decorrente dos altos valores das instituições privadas, seja pela não existência de benefícios trabalhistas relacionados ao cuidado a esse público. Tal resultado evidencia que as famílias requerem maior aporte público no financiamento dos custos no cuidado aos idosos. Apesar da grande proporção de responsabilização da família por esse cuidado $(86.5 \%)$, próximo de $40 \%$ dos informantes consideraram que éo Estado que deveria, preferencialmente, cobrir os custos financeiros desse cuidado.

\section{Considerações finais}

Nesse artigo visamos analisar as percepções de homens e mulheres do estado do Rio de Janeiro sobre a responsabilidade do cuidado às crianças

\footnotetext{
7 Os cruzamentos da pergunta foram significativos somente para os homens (homens Pearson chi-quadrado $=$ ,000).

${ }_{8}^{8}$ Os cruzamentos da pergunta foram significativos somente para os homens (homens Pearson chi-quadrado = ,000).
} 


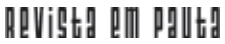

\} PERCEPÇÕES SOBRE O PAPEL DAS POLÍTICAS PÚBLICAS - GAMA, A. S.; ROCHA, L. M.;ALCANTARA, K. R. \}

DOI 10.12957/REP.2017.30379

pequenas e aos idosos dependentes, bem como sobre o papel que atribuem às políticas públicas relacionadas ao conflito entre trabalho remunerado e trabalho do cuidado na família.

Identificamos que ainda prevalece uma percepção que atribui eminentemente às famílias o cuidado às crianças pequenas e aos idosos dependentes.

Em grande parte dos países desenvolvidos, as licenças trabalhistas remuneradas têm um importante papel na tentativa de equilibrar as demandas laborais e de cuidado às crianças pequenas. Constatamos que a percepção dos informantes é marcada por um forte traço maternalista no gozo dessas licenças, na mesma direção do que concebe a legislação trabalhista brasileira. Por outro lado, verificamos uma tendência de ampliação do tempo da licença-paternidade, principalmente entre os homens, o que revela uma novidade em termos da visão da paternidade na sociedade e a consequente demanda pela extensão desse direito trabalhista. As respostas indicam que a percepção sobre o atual formato da licença-paternidade está obsoleto e/ ou insuficiente na medida em que há uma demanda dos próprios atores por mais tempo no gozo dessa licença.

Algumas ponderações devem ser feitas para dimensionar os resultados ora apresentados. Em primeiro lugar, é necessário destacar que, historicamente, o arranjo institucional do sistema de proteção social brasileiro mesmo após a Constituição de 1988 - esteve assentado sobre a provisão familiar de cuidados como instância primária de proteção. Diversos estudos já demonstraram o papel da família na sociedade brasileira e os mecanismos de normatização do Estado para que essa exerça com eficiência seu papel de cuidadora.

Em segundo lugar, o trabalho e o Estado no Brasil não estão presentes da mesma forma nem têm o mesmo poder de interferência na organização da reprodução social nos diferentes grupos socioeconômicos.Existe uma estreita relação entre a inserção desigual das mulheres no mercado de trabalho e o acesso diferencial aos suportes de cuidado pelo mercado e Estado e na divisão sexual do trabalho doméstico (SORJ; FONTES, 2012; GAMA, 2014).

O que queremos dizer é que a trajetória político-institucional da proteção social brasileira, ao não externalizar as demandas de cuidado das famílias associado às desigualdades de gênero no mercado de trabalho, criou um caldo cultural que cristalizou concepções tradicionais de gênero em relação ao compartilhamento dessas responsabilidades com o Estado e o mercado. Em verdade, há uma influência recíproca entre as percepções dos informantes acerca do desempenho das políticas públicas relacionadas aos cuidados e à conformação dessas políticas, que reforçam visões tradicionais.

No tocante à divisão das responsabilidades com o cuidado das crianças abaixo da idade escolar e aos idosos dependentes, entre Estado, 
família e mercado, apesar de a família ser a principal responsável pelo cuidado, constatamos que essa responsabilidade é maior em relação aos idosos dependentes do que em relação às crianças pequenas. Percebe-se uma aceitação maior do compartilhamento dos cuidados com as crianças com outras instituições não familiares do que com os idosos. Tais percepções podem estar assentadas na maior aceitação das instituições de educação infantil do que naquelas direcionadas aos idosos, caracterizadas pelo histórico de abandono, negligência e baixa cobertura dos serviços públicos, e pelos altos custos dos serviços privados.

Entretanto, quando perguntados sobre os custos financeiros dos cuidados a esses grupos, tal responsabilidade se inverte. Há uma maior responsabilização do Estado, especificamente no financiamento do cuidado aos idosos, comparado às crianças pequenas. Esse resultado evidencia que as famílias requerem maior aporte público no financiamento dos custos do cuidado aos idosos dependentes. Provavelmente, contribuem para essa percepção a arquitetura da Previdência e da assistência social brasileira, que possui ampla cobertura de benefícios em dinheiro vis-à-vis à inexistência de benefícios monetários universais direcionados às crianças, como existente em outros países.

Verificamos que estar inserido no mercado de trabalho está associado aos maiores percentuais relacionados ao compartilhamento desse cuidado com as outras instituições de proteção social. Estar trabalhando foi uma variável mais relevante do que ter filhos em percepções menos conservadoras relativas ao cuidado. Esse resultado indica os dilemas associados à inserção produtiva e ao cuidado como uma necessidade premente relacionada ao mundo do trabalho. No entanto, há que se reforçar que as políticas públicas abranjam não somente a esfera pública (trabalho), como também a esfera privada (família). Tais medidas podem incentivar uma maior igualdade de gêneros na divisão dos trabalhos, sejam eles produtivos ou reprodutivos.

Por fim, a pesquisa evidencia que, para superar os ordenamentos de gênero, as políticas públicas direcionadas aos cuidados necessitam ser ampliadas e desmercantilizadas, frente às desigualdades de gênero no mercado de trabalho e no interior da família. Identificamos uma chave de questões que apontam para a interdependência da concepção política e do arcabouço jurídico-institucional das políticas sociais, bem como para as percepções de homens e mulheres trabalhadores acerca da amplitude dessas políticas e do papel desempenhado pelas famílias na provisão de cuidados.

A problematização dos sistemas de cuidados como gerador de bem-estar econômico e social pode avançar mediante a continuidade desse tipo de investigação, que tem como foco principal as percepções dos trabalhadoressobre as políticas sociais. 
\} PERCEPÇÕES SOBRE O PAPEL DAS POLÍTICAS PÚBLICAS - GAMA, A. S.; ROCHA, L. M.;ALCANTARA, K. R. \}

DOI $10.12957 /$ REP.2017.30379

\section{Referências}

ARAÚJO, C.; SCALON, C. Percepções e atitudes de mulheres e homens sobre a conciliação entre família e trabalho pago no Brasil. In: Gênero, família e trabalho no Brasil. Rio de Janeiro: Editora FGV, 2005.

BRUSCHINI, C.; LOMBARDI, M. R. A bipolaridade do trabalho feminino no Brasil contemporâneo. Cadernos de Pesquisa, n. 110, jul. 2000.

CAMARANO, A. A. Cuidados de longa duração para a população idosa. Sinais Sociais, v. 3, 2008.

FONSECA, C. Ser mulher e pobre. In: PRIORE, M. D. (Org.). História das mulheres no Brasil. São Paulo: Contexto, 2002.

GAMA, A. S. Trabalho, família e gênero - impactos dos direitos do trabalho e da educação infantil. São Paulo: Cortez, 2014.

KNIJN, T.; UNGERSON, C. Introduction: care work and gender in welfare regimes. Social Politics, v. 1 n.1, 1997.

JENSON, J. Who cares? Gender and welfare regimes. Social Politics v. 4, n. 2, 1997.

LAVINAS, L.; DAIN, S. Proteção social e justiça redistributiva: como promover a igualdade de gênero. Rio de Janeiro: Fase, 2005.

LEWIS, J. The decline of the male breadwinner model: the implications for work and care. Social Politics, v. 8, n. 2, 2001.

O'CONNOR, J. S.; ORLOFF, A. S. SHAVER, S. States, markets, families. Gender, liberalism and social policy in Australia, Canada, Great Britain and the United States. Cambridge: Cambridge University Press, 1999.

SAINSBURY, D. Gender and the making of Welfare States: Norway and Sweden. Social Politics, v. 8, n. 1, 2001.

SARACENO, C. A dependência construída e a interdependência negada. Estruturas de gênero da cidadania. In: BONACCHI, G.;GROPPI, A.(Org.). O dilema da cidadania: direitos e deveres das mulheres. São Paulo: Ed. Universidade Estadual Paulista 1995.

SORJ, B. Reconciling work and family: issues and policies in Brazil. Geneva: International Labour Office, 2004.

SORJ, B.; FONTES, A. O care como um regime estratificado: implicações de gênero e classe social. In: HIRATA, H.; GUIMARÃES, N. A. (Org.) Cuidado e cuidadoras - as várias faces do trabalho do care. São Paulo: Atlas, 2012. 


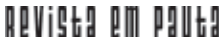

\} PERCEPÇÕES SOBRE O PAPEL DAS POLITICAS PÚBLICAS - GAMA, A. S.; ROCHA, L. M.;ALCANTARA, K. R. \} DOI 10.12957/REP.2017.30379

Recebido em 04 de agosto de 2016.

Aprovado para publicação em 19 de novembro de 2016. DOI 10.12957/rep.2017.30379

\section{(c) (†)}

A Revista Em Pauta: Teoria Social e Realidade Contemporânea está licenciada com uma Licença Creative Commons Atribuição 4.0 Internacional.

EM PAUTA, Rio de Janeiro - $1^{\circ}$ Semestre de 2017 - n. 39, v. 15, p. 106 - 128 